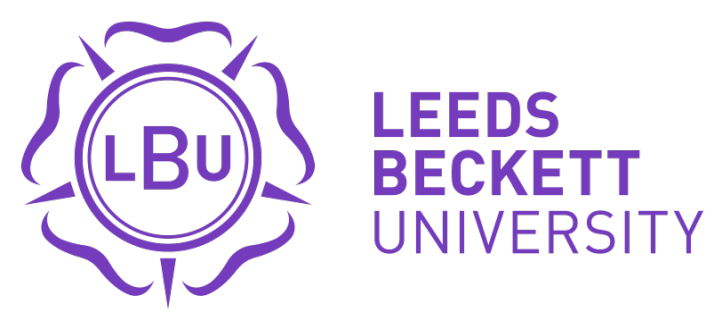

Citation:

Witty, K and Branney, P and Bullen, K and White, A and Evans, J and Eardley, I (2014) Engaging men with penile cancer in qualitative research: reflections from an interview-based study. Nurse researcher, 21 (3). 13 - 19. ISSN 1351-5578 DOI: https://doi.org/10.7748/nr2014.01.21.3.13.e1218

Link to Leeds Beckett Repository record:

https://eprints.leedsbeckett.ac.uk/id/eprint/228/

Document Version:

Article (Accepted Version)

The aim of the Leeds Beckett Repository is to provide open access to our research, as required by funder policies and permitted by publishers and copyright law.

The Leeds Beckett repository holds a wide range of publications, each of which has been checked for copyright and the relevant embargo period has been applied by the Research Services team.

We operate on a standard take-down policy. If you are the author or publisher of an output and you would like it removed from the repository, please contact us and we will investigate on a case-by-case basis.

Each thesis in the repository has been cleared where necessary by the author for third party copyright. If you would like a thesis to be removed from the repository or believe there is an issue with copyright, please contact us on openaccess@leedsbeckett.ac.uk and we will investigate on a case-by-case basis. 


\section{Engaging men with penile cancer in qualitative research: Reflections from interview-based study.}

Keywords: Interviewing, Men, Sensitive Conditions, Penile Cancer.

\section{Abstract}

Aims: To explore the challenges of engaging men with penile cancer in qualitative interview research.

Background: Qualitative interviewing offers an ideal tool for exploring men's experiences of illness, complementing and providing context to gendered health inequalities identified within epidemiological research on men. But, conducting interview research with men can be challenging and with limited practical, gender sensitive guidance for researchers, embarking on a qualitative interview study with men can feel like a daunting task. Reflecting on a researcher's experience of conducting qualitative research on men with penile cancer, the current paper explores the potential challenges of interviewing this group of men, but also documents how engagement and data collection was achieved.

Review methods: This is a reflective paper, informed by the experiences of a male researcher with no nurse training, conducting 27 interviews with men who have been treated for penile cancer. Researcher experience is reported in chronological order, from the methodological challenges of recruitment to those of conducting the interview itself. Conclusion: Engaging men with penile cancer in a qualitative interview study raises practical, methodological, ethical and emotional challenges for the researcher, however, in reflecting on interviews conducted with men who have received treatment for penile cancer the authors challenge false assumptions that men will not talk about their ill health. Methodological procedures must enable an open and on-going dialogue with clinical 
gatekeepers and potential participants to promote engagement. Emotional and practical support from colleagues is an essential for any interviewer, no matter how experienced.

Implications for practice/research: The paper offers a resource for the novice researcher, highlighting some advantages and disadvantages of conducting qualitative interview research in a nurse researcher role as well as recommendations on how to overcome key challenges. 


\section{Introduction}

There is a historical bias towards, and a reliance upon quantitative methods to acquire universal knowledge (Carr, 1994). For many health practitioners evidence-based practice is intrinsically linked to the use of empirical, quantitative research; the randomised controlled trial and the 'gold standard' systematic review (Noyes, 2010). Within men's health quantitative, epidemiological research such as that documented in the recent 'State of men's health in Europe Report' (European Commission., 2011) continue to provide the primary means of examining men's issues (Oliffe and Mróz, 2005).

Quantitative data is sometimes referred to as 'hard' scientific data, positioned against 'soft' qualitative data, a distinction which not only implies quantitative method holds greater robustness (Corner, 1991), but ties in with conceptualisations of idealised gender roles; the hardy, stoic and enduring male and the softer, docile, and subservient female. White and Johnson (1998) noted the expectation that feminist research was centralised onto women's stories in some form of unique female researcher's prerogative. Such that not only is the interview viewed as a threat to men's masculinity (Schwalbe and Wolkomir, 2001) or problematic but, following suggestions with the literature that men do not readily express themselves (Oliffe and Mróz, 2005) we reach a default position that the interview appears to be an inappropriate method for researching men.

Challenging these assumptions, researchers in nursing and men's health are increasingly turning to qualitative methods to provide context (Oliffe and Mróz, 2005, White and Johnson, 1998) and further insight to quantitative data, which reveals widespread health 
inequalities experienced by men (White, 2011). Qualitative research, such as in-depth interviewing is being recognised as providing an ideal tool for exploring patient experience and the complexities of men's subjective lives (Hutchinson et al., 2002) and particularly apt when the topic being researched is of a sensitive nature (Elmir et al., 2011). The growing body of qualitative research focused around men's experiences of ill health would indicate, counter to many false assumptions, some men will talk about their ill health (see for example (Ervik and Asplund, 2012, Bullen et al., 2010, Oliffe et al., 2010) but, with the notable exception of Oliffe and Mróz's (2005) guidance paper, there is limited practical advice for researchers on how to engage men in qualitative research.

Reflecting on the experiences of a researcher without nurse training, conducting a narrative interview study with 27 men treated for penile cancer, this paper offers a first person experientially informed account of interviewing men, and adds to literature which challenges false assumptions that men will not talk about their ill health. In doing so the paper offers a de-sanitised account of conducting qualitative interviewing for the novice nurse-researcher. Secondly, in highlighting some of the challenges of conducting interviews as a non-nurse-researcher the paper accentuates the many advantages (and some disadvantages) of conducting qualitative nurse-research.

\section{Penile Cancer and The PEPC study}

Penile cancer is a rare squamous cell carcinoma (SCC), with approximately 400 new cases diagnosed in the UK each year (Macmillan Cancer Support, 2013), although prevalence in the developing world is often reported to be considerably greater (Bleeker et al., 2009, Misra et al., 2004). Survival rates in the UK are high, with more than $80 \%$ of men presenting early stage cancer living beyond five years (Branney et al., 2011). The standard 
treatment is to surgically remove the primary tumour; the extent of the excision is determined by the size and staging of the cancer (Pizzocaro et al., 2010). Whilst treatment is usually effective, the physical and psychological effects can be profound (Opjordsmoen and FossÅ, 1994), impacting not only on the form and function of the penis (Maddineni et al., 2009, Branney et al., 2011) but also on the self-image and mental well-being of those receiving treatment (Ficarra et al., 2000, Romero et al., 2005, Bullen et al., 2010).

\section{Design and Methods}

Patient's Experiences of Penile Cancer (PEPC) was a UK-wide study that aimed to explore and understand men's experiences of the diagnosis, treatment and impact of penile cancer. The study was undertaken in collaboration with the Health Experiences Research Group from the University of Oxford. The PEPC study adopted the standard methods and consent procedures for all studies to be published on www.healthtalkonline.org. NHS ethics approval was in place before the study began. A thematic analysis illustrated by clips from the interviews can be found at http://www.healthtalkonline.org/Cancer/Penile_cancer.

As with all healthtalkonline studies, purposive sampling was used with the aim of recruiting a maximum variation sample to include the broadest practicable range of experiences from people treated for the condition across the UK. PEPC employed a three-part model: pilot, main study and evaluation. The main phase of the study, which is the subject of this paper, consisted of one-on-one narrative interviews that were usually conducted in the participant's home. Depending on the preferences of the participants, these interviews were recorded using either a video camera or audio recorder so that quotes could be presented on www.healthtalkonline.org as short video or audio clips, or as text-only. As such, the challenges of research on penile cancer were amplified because the research team 
were asking potential participants to take part in a study where their personal journey would be made 'public' on the internet and where, even if they chose text-only quotes for anonymity, some men might reveal their identity to people who knew them through what they said.

All interviews were conducted by me (XX), a young(ish), mild mannered, White, middle class, heterosexual, male researcher, with no nurse training or experience of nursing, working within a Northern English academic institution. Throughout the interview process I received support and guidance from an experienced female researcher (a healthtalkonline research 'buddy') located within another academic institution (XX) and from a male research team consisting of academics, a registered nurse, and senior urological consultant ( $X X, X X \& X X)$. Further support was provided by an advisory group which consisted of academics, key figures in the world of men's health, senior health professionals and lay experts.

\section{Recruitment}

It was agreed with the study's funder that 20 to 25 interviews was a reasonable, albeit potentially challenging, recruitment target for such a rare condition. Three strategies to reach potential participants were employed, these were: 1) Advertisement of the study through a range of paper and online publications and through existing professional networks of partner organisations; 2) Recruitment through eight NHS gatekeepers situated in specialist supranetwork multidisciplinary teams (Sn-MDTs) distributed across the UK; 3 ) Face-to-face recruitment at a local supranetwork for which the research team had secured research governance approvals to meet patients on-site. 
The three recruitment strategies produced very different results. Advertisements yielded just one response and no participants for the study. The lack of focus of this strategy combined with the rarity, and sensitivity of the condition meant there was only a slim chance of recruiting men in this way, however, as little researcher input was needed to implement the strategy it was a worthwhile exercise.

UK Guidelines (NICE, 2002) recommend that penile cancer healthcare services are delivered through specialist supranetwork multidisciplinary teams (Sn-MDTs) that see at least 25 new diagnoses per annum, thus, Sn-MDTs offered a recruitment hub for the study. Consultants from eight of these supranetworks agreed to help with recruitment and several consultants provided the research team with the contact details of a nurse specialist or nurse researcher who could approach potential participants on our behalf. Over 200 recruitment packs were distributed to these gatekeepers. Initially, recruitment was limited, with just one supranetwork providing patients, where the clinicians and the study's principle investigator (XX) had met in-person and discussed patient recruitment. Consequently, we drew upon our links with a local penile cancer consultant $(X X)$ and a nurse specialist who phoned colleagues at the other supranetworks to talk about the study and explain what was involved. Subsequently, recruitment improved and elicited 18 participants ( 2 patients subsequently withdrew from the study) seemingly indicating the relative ease with which the nurseresearcher can access potential participants (Bonner and Tolhurst, 2002).

In common with previous accounts of conducting research with men, the face-to-face recruitment between the researcher and the patients proved to be more successful (Oliffe and Mróz, 2005). Whilst requiring a greater investment of researcher time, face-to-face recruitment within a local NHS site provided a mechanism for delivery of a highly targeted strategy, a key advantage when recruitment is focussed on a relatively small population of 
patients with complex needs such as was the case within the PEPC study. Furthermore, face-to-face recruitment enabled me to build up trust and develop rapport with participants at an early stage in the research process. The compromise of adopting this strategy was the limit to geographical spread that was introduced into the sample, with over one third of men recruited from a single Sn-MDT. Furthermore, in recruiting within a clinical setting, sometimes minutes after patients had attended consultations with a health professional, some patients presented strong emotions which, in one instance I felt ill equipped to attend to as a researcher with no training in delivering therapeutic interventions.

Recruitment of participants was one of the most challenging stages of the study. With all strategies initially falling short of targets and having limited means of accessing patients, I experienced feelings of disempowerment and demoralisation. Combined with mounting pressures to achieve project deadlines, this proved to be a highly stressful stage of the process.

These challenges were met by adopting a pragmatic approach to the task, focussing efforts on proven recruitment strategies, which for this study was face-to-face recruitment of men within a local NHS site. Inevitably, this approach somewhat compromised the geographic diversity of the sample, but, more importantly this approach enabled us to complete the study and broadly achieve study objectives.

\section{From contact to interview}

Multi-step informed consent process 
The time between first contact and interview was an important stage of the PEPC study for informing potential participants about the research and developing rapport. PEPC followed the healthtalkonline standard multi-step informed consent process before the interview in which:

1. Information was relayed in a variety of formats (written, in-person, over-thetelephone).

2. There were multiple opportunities for potential participants to ask questions.

3. Potential participants had time to think about their involvement and, if they wished, discuss it with family, friends and healthcare professionals.

Standardised procedures for administering written information sheets were part of a broader ethical and moral framework (Miller and Boulton, 2007) in which consent was an on-going dialogue between myself and the potential participant. Potential participants signalled their interest in partaking in the study by sending a reply-slip (which was part of the recruitment pack) in a stamped addressed envelope to the research team. Consistent with other researchers' accounts of researching men's health (Walls et al., 2010, Oliffe and Mróz, 2005) upon contacting respondents, I found that few men appeared to have read the participant information sheet before returning the reply-slip. In some cases, predominantly with the older men, there appeared to be little understanding of what involvement in the study would mean and some men appeared to be willing to blindly engage with the research, unconcerned with the details of what participation would involve. In such instances I experienced the conflicting desires of protecting the interests of research participants, but also meeting their wishes in conducting the interview and collecting data. Men's motivations for taking part in the study included a wish to help other men diagnosed with penile cancer by sharing their experiences, a wish to repay the health professionals 
who treated them for the quality of care they received, and to encourage self-reflection, helping them generate understanding of their own experiences and aid their further recovery.

In order to promote a greater understanding of risks of taking part in the study, I attempted to verbalise the potential risks, stressing the insecurities of anonymity when presenting data on the internet and using hypothetical scenarios where anonymity could be compromised. Previous research on strategies to improve research participants' understanding of the risks of participation in research as part of the consent process has indicated that investing time talking with study participants and tailoring communication to meet their needs may be the most effective means of improving understanding of research (Flory and Emanuel, 2004, Locock and Smith, 2011).

Arranging the time and place of the interview

In arranging a time and location of each interview, I tried to be flexible to meet the needs of the participant. Most participants were happy to be interviewed in their own homes, but some asked for their interview to be conducted in an alternative setting. The reasons behind men's choices of location were not always apparent; however, as has been found in a previous study, it appeared that one had anxieties about inviting a researcher into his home (Walls et al., 2010).

The majority of men were happy for me to suggest a date for the interview. This meant that interviews could be grouped according to geographic location, thus conserving time and resources. When there was a time lapse of more than a few days between agreeing a date and holding the interview, I would confirm the appointment closer to the agreed date. 
Whilst it was initially intended that I would conduct no more than one interview per day, strict project deadlines meant that it was not always possible to adhere to this plan.

\section{Arriving at the interview location}

When arriving at the interview venue I consciously presented a mild mannered, noncompetitive but professional (Oliffe and Mróz, 2005) masculine self, and allowed the participant set the tone of the interaction. Many men used humour from the offset, acknowledging that this may have been a coping strategy, a buffer against stress (Healy and McKay, 2000) and generally men presented themselves as relaxed and comfortable with their role in the research. Others displayed anxieties about their participation in the research, commonly linked to how the data would be used and presented and possible breaches of anonymity.

Before conducting the interview itself I explained the study and the consent process and gave a demonstration of how clips from their interview would be presented on www.healthtalkonline.org. For some men, this demonstration appeared to help them set the tone of their narratives. For other men it was difficult to establish what benefit, if any, was gained from the demonstration, although, as an interviewer I found it to be a useful tool for developing conversation and building rapport.

Having time to build up further rapport before the interview is often valuable for the qualitative researcher (Al-Yateem, 2012, Oliffe and Mróz, 2005). Pre-interview conversation enabled me to gain insight into the personality, mental and emotional wellbeing of each participant, how they appeared to be coping with the impact of their condition and which topics, if any they were not comfortable talking about. This insight was not gained through 
the use of any psychometric scales or screening tools, and therefore may have been scientifically unreliable. But for me, as an interviewer without nurse training, using my social skills to collect information in a subtle and sensitive manner offered a highly appropriate means of generating my own perceptions of how the man was coping, which within the context of my relationship with the interviewee was valid. With this information, I was able to make an informed judgement on the appropriate line of questioning to take for each individual interviewee; omitting questions which probed deeply into issues which the participant had indicated were personally problematic. I used constant reflection (Hayter, 2010) and an empathic approach to help ensure that questions were both justified and appropriate for each individual man.

Within this discussion period, several men expressed interest in my background and aspects of my personal life, an occurrence which I perceive may not be as common within the more established and defined nurse-patient relationship. Whilst conscious to avoid diverting attention from the purpose of the study I was also mindful that I could not ask the participant to reveal details of an extremely personal and sensitive experience without investing in the relationship myself (Eide and Kahn, 2008). Developing rapport whilst maintaining a professional distance was a constant struggle over the course of the study but something I was particularly mindful of given the vulnerability of some of the men I was interviewing.

\section{The Interview}

The nature of the topic, the method and the recording technology all had implications for the conduct of the interviews. The participants were split evenly between those who consented for their narratives to be recorded and presented on the website in video format 
and those who preferred audio format (see Table 1). On the whole, men who requested their interview to be video recorded presented a relaxed persona and appeared to be the most at ease with sharing their experiences. In instances where men expressed a strong concern over potential breaches of anonymity, I actively discouraged them from being recorded on video, feeling this was a suitable compromise between their wishes to be involved in the study and concerns over anonymity.

\section{Table 1 - Format for presenting data for which consent was given}

Despite being a practiced interviewer, I felt nervous, being faced with the challenges of eliciting discussion on such a sensitive topic and producing a high quality recording whilst at the same time attending to the needs of the interviewee.

\section{Eliciting narratives}

Before commencing the interview, I explained to the participant the format that the interview would take, provided examples of some of the topics they might wish to talk about during the interview and asked them if they wished to see the interview schedule. A small proportion of men appeared to appreciate having insight into the type of questions to be asked, not wanting to be caught 'off-guard' by unexpected questions, whilst others seemed to prefer to provide more spontaneous answers. None of the men asked to exclude specific questions from the interview schedule.

I began each interview with, 'Please tell me the story of your illness from when you first suspected a problem'. The inclusion of a broad, open-ended question at the start of the interview is standard for all healthtalkonline studies and meant that each participant was 
able to set the agenda for discussion and relate their narrative in a way in which they were most comfortable. Once participants had completed their uninterrupted narrative, supplementary questions, prompts and probes were used to elicit more content on topics such as symptoms, help seeking, diagnostic processes, treatment and its impacts. Supplementary questions had been developed, in part, through a patient-led pilot workshop held before the main phase of the study.

In line with other accounts of researching sensitive topics (Walls et al., 2010), many men initially gave little detail of their experience in their opening narrative, although some of these did open up in response to questions and probes from me as the interview progressed. Some men who had been open and free flowing in conversation before commencing the interview, gave short answers sometimes more formal in tone once the interview had commenced. I attempted to overcome these limited responses to questions by encouraging responses through verbal and in some instances subtle physical gesturing, probing with rephrased and more targeted questioning and using prompts to elicit more detail. With hindsight, signposting men, asking if they could save narratives for the interview may have helped mediate this effect.

In several instances, men displayed strong emotions, sometimes crying. Questions about the impact of penile cancer on men's relationships were often the trigger for this release. If I felt men were becoming too distressed I offered to pause the interview. All men who took up this offer wished to continue with the interview after a short break. While conscious that I had inadequate training to attend to men's health and wellbeing needs personally, I was able to provide men with information on relevant help services within their area. 
In common with findings from a Welsh study (Bullen et al., 2010) men's narratives of masculinity were interlaced with a hegemonic discourse of stoicism, independence, robustness and resiliency. Some researchers have found that this enactment of 'maleness' is a barrier to the in-depth, nuanced account of experiences that interviews seek (Oliffe and Mróz, 2005). In several of the PEPC interviews, the participants focused on their positive regard for the treatment and associated healthcare professionals, often to the detriment of a more critical account of how such care impacted on their health and wellbeing. I found that using subtle prompts such as, 'would you feel comfortable telling me a bit more about that?' were often a more effective way of eliciting greater detail on the impact of treatment than asking direct questions about impact, which could close off topic areas. However, there were also cases where such probing seemed to irritate the participant (Oliffe and Mróz, 2005).

In some instances, it is possible that discussion was also curtailed by me as an interviewer, my own inhibitions and a reluctance to raise questions which I thought (accurately or not) could cause distress to the interviewee. This sensitivity may have inhibited discussion of the potentially more delicate aspects of men's experiences, for example post treatment sexual functioning, particularly in those interviews where a strong rapport had not been developed. Again, having time to talk to the participant before the interview, discuss any topics which they would not feel comfortable talking about as part of the interview and further develop the researcher participant relationship helped me make a more informed judgement on the appropriate line of questioning.

\section{Debriefing}


After each interview, I engaged in reflective discussion with the interviewee. Within this debrief, several participants continued to present uncertainty about the purpose of the research and my role. Some participants presented challenging questions, for example, requesting medical information on the causes of penile cancer, guidance on treatment options, and one wanted advice on sexual functioning. In response to these questions I repeated that I had no medical training and recommended that the participant speak to his penile cancer specialist or general practitioner.

Following debrief, conversation tended to digress away from the project. Several men talked about their hobbies or showed me their house or gardens; I felt that this casual conversation helped some of the men to collect themselves after revealing such intense emotion. It was also beneficial for me as a researcher, providing further context to what the men had revealed within the interview and also reassuring me that emotional equilibrium had been restored.

\section{After the interview}

The interviews were transcribed verbatim and participants given an opportunity to review the content of the transcript and the format (video, audio or text only) that they wanted their clips to appear on the website, before giving final permission for their interview to be used on www.healthtalkonline.org. One man chose to drop out of the study after receiving his interview transcript, concerned that he came across as inarticulate. There were no significant amendments to the transcripts requested by the other participants.

\section{The impact of/on the Interviewer}


The pilot phase of the study had highlighted some men's anxieties of telling their story of penile cancer in front of women, validating our enforced approach of conducting all interviews with a male researcher. However, as has been noted in previous literature, presenting a male interviewer to a male participant may encourage the enactment of idealised notions of manliness, for example through exertion of control and dominance (Schwalbe and Wolkomir, 2001, Broom et al., 2009, Oliffe and Mróz, 2005), which may limit rapport building and performance within the interview. Whilst there were instances where this may have occurred I was more conscious of the impact of other elements of my biography (Broom et al., 2009) which I brought to the interview, most notably my perceived youth my status as a full time researcher and my relatively passive style of interviewing. These traits, along with the methods used to elicit men's narratives appeared to situate me in a role which invited men to dominate the interview, but in a non-competitive way, enabling men to relate their narratives in a manner in which they felt comfortable. In reflection I also felt comfortable with this dynamic given the sensitivity of the topic, as it enabled me to adopt a position, as an interviewer, which I perceived to be less threatening to the interviewee. On a conscious level, I did very little to adapt my interactions with men to compensate for what may be considered vulnerable masculinities.

I felt privileged to be party to men's personal narratives; particularly in those cases where men had not disclosed their illness to people outside their family and healthcare team. After interviews I often felt uplifted by the positivity of men's accounts, however, interviewers may carry an emotional burden from interviews, which can be amplified when researching a sensitive topic (Dickson-Swift et al., 2008, Sampson et al., 2008, White and Johnson, 1998). When participants released deep emotion, sometimes breaking down in tears, I could feel guilty for having facilitated a release of such emotions whilst being unable to attend to them in any therapeutic sense. Within these instances I was made very conscious of my lack of 
nurse training, experiencing a desire to attend to men's emotional distress but lacking the skills to do so. These feelings were most notably present in me when interviewing participants who had presented vulnerabilities or strong concerns about their participation in the research before the interview.

Presenting myself as a researcher with no medical training from the offset of the relationship, men were made aware that I was not a person who was there to help heal any emotional scars resulting from their experiences, a strategy which a nurse-researcher would not be able to engage, potentially resulting in a struggle to balance the two roles (Breen, 2007).

While I was conscious to avoid burdening myself with the often difficult experiences of the participants, and experiencing emotional trauma vicariously, I was nevertheless aware that distancing or de-sensitising myself to the topic could impede further engagement with participants. Given the nature of the topic, this issue was unavoidable and something I struggled with throughout the study. Reflective discussion with the wider research team was an important process in maintaining my wellbeing as a researcher.

\section{Conclusion}

In engaging men who have been diagnosed and treated for penile cancer in the PEPC study the researcher faced practical, methodological, ethical and emotional challenges. The rarity of penile cancer and the limited access which a non-nurse-researcher has to patients meant that the research team faced the challenge of gaining access to a small, geographically dispersed population. The sensitivity of the topic raised the importance of trust, anonymity, confidentiality and introduced further concerns relating to the health and wellbeing of both 
interviewee and researcher. In conducting interviews with men, the team were faced with a traditional notion of men as 'strong and silent' (Mackereth and Milner, 2009). Nevertheless, PEPC successfully recruited and interviewed 27 men.

To ensure successful recruitment of men with a rare condition, methodological procedures need to enable a dialogue between the researchers, clinical gatekeepers and potential participants. Discussion between the researchers and clinical gatekeepers can help ensure they are clear about study aims, thus aiding recruitment. If recruitment strategies are not working researchers must adopt a pragmatic approach, adapting methods of recruitment in order to achieve key objectives Experience is crucial, whether the interviewer is a nurseresearcher or a researcher with no nurse training, not only for their skills in data collection (i.e. interviewing) but also their ability to communicate with potential participants and develop rapport. However, even experienced interviewers will require support from other members of the research team or clinical team throughout the study to allow reflective discussion about the research process. 


\section{References}

AL-YATEEM, N. 2012. The effect of interview recording on quality of data obtained: a methodological reflection. Nurse Researcher, 19, 31-35.

BLEEKER, M., HEIDEMAN, D., SNIJDERS, P., HORENBLAS, S., DILLNER, J. \& MEIJER, C. 2009. Penile cancer: epidemiology, pathogenesis and prevention. World Journal of Urology, 27, 141-150.

BONNER, A. \& TOLHURST, G. 2002. Insider-outsider perspectives of participant observation. Nurse Researcher, 9, 7-19.

BRANNEY, P., WITTY, K. \& EARDLEY, I. 2011. Patients' experiences of penile cancer. European Urology, 59, 959-61.

BREEN, L. J. 2007. The researcher 'in the middle': Negotiating the insider/outsider dichotomy. The Australian Community Psychologist, 19, 163-174.

BROOM, A., HAND, K. \& TOVEY, P. 2009. The role of gender, environment and Individual biography in shaping qualitative interview data. International Journal of Social Research Methodology, 12, 51-65.

BULLEN, K., EDWARDS, S., MARKE, V. \& MATTHEWS, S. 2010. Looking past the obvious: experiences of altered masculinity in penile cancer. Psycho-Oncology, 19, 933-940.

CARR, L. T. 1994. The strengths and weaknesses of quantitative and qualitative research: what method for nursing? Journal of Advanced Nursing, 20, 716-721.

CORNER, J. 1991. In search of more complete answers to research questions. Quantitative versus qualitative research methods: is there a way forward? Journal of Advanced Nursing, 16, 718-727.

DICKSON-SWIFT, V., JAMES, E. L., KIPPEN, S. \& LIAMPUTTONG, P. 2008. Risk to Researchers in Qualitative Research on Sensitive Topics: Issues and Strategies. Qualitative Health Research, 18, 133-144.

EIDE, P. \& KAHN, D. 2008. Ethical Issues in the Qualitative Researcher-Participant Relationship. Nursing Ethics, 15, 199-207.

ELMIR, R., SCHMIED, V., JACKSON, D. \& WILKES, L. 2011. Interviewing people about potentially sensitive topics. (Cover story). Nurse Researcher, 19, 12-16.

ERVIK, B. \& ASPLUND, K. 2012. Dealing with a troublesome body: A qualitative interview study of men's experiences living with prostate cancer treated with endocrine therapy. European Journal of Oncology Nursing, 16, 103-108.

FICARRA, V., RIGHETTI, R., D'AMICO, A., PILLONI, S., BALZARRO, M., SCHIAVONE, D., MALOSSINI, G. \& MOBILIO, G. 2000. General State of Health and Psychological WellBeing in Patients after Surgery for Urological Malignant Neoplasms. Urologia Internationalis, 65, 130-134. 
FLORY, J. \& EMANUEL, E. 2004. Interventions to improve research participants' understanding in informed consent for research: a systematic review. JAMA, 292, 1593-601.

HAYTER, M. 2010. Editorial: Researching sensitive issues. Journal of Clinical Nursing.

HEALY, C. M. \& MCKAY, M. F. 2000. Nursing stress: the effects of coping strategies and job satisfaction in a sample of Australian nurses. Journal of Advanced Nursing, 31, 681688.

HUTCHINSON, S., MARSIGLIO, W. \& COHAN, M. 2002. Interviewing young men about sex and procreation: methodological issues. Qualitative Health Research, 12, 42-60.

LOCOCK, L. \& SMITH, L. 2011. Personal experiences of taking part in clinical trials - a qualitative study. Patient Education and Counseling, 84, 303-9.

MACKERETH, C. \& MILNER, S. J. 2009. 'He'll not talk to anyone': researching men on low incomes. Community Practitioner, 82, 24-27.

MACMILLAN CANCER SUPPORT. 2013. Penile cancer (cancer of the penis) [Online]. Available: http://www.macmillan.org.uk/Cancerinformation/Cancertypes/Penis/Penilecancer.a spx [Accessed February 2013].

MADDINENI, S., LAU, M. \& SANGAR, V. 2009. Identifying the needs of penile cancer sufferers: A systematic review of the quality of life, psychosexual and psychosocial literature in penile cancer. BMC Urology, 9, 8.

MILLER, T. \& BOULTON, M. 2007. Changing constructions of informed consent: Qualitative research and complex social worlds. Social Science and Medicine, 65, 2199-2211.

MISRA, S., CHATURVEDI, A. \& MISRA, N. C. 2004. Penile carcinoma: a challenge for the developing World. The Lancet Oncology, 5, 240-247.

NICE 2002. Improving Outcomes in Urological Cancers: The Manual. London.

NOYES, J. 2010. Never mind the qualitative feel the depth! The evolving role of qualitative research in Cochrane intervention reviews. Journal of Research in Nursing, 15, 525534.

OLIFFE, J. \& MRÓZ, L. 2005. Men interviewing men about health and illness: ten lessons learned. The Journal of Men's Health \& Gender, 2, 257-260.

OLIFFE, J. L., ROBERTSON, S., KELLY, M. T., ROY, P. \& OGRODNICZUK, J. S. 2010. Connecting Masculinity and Depression Among International Male University Students. Qualitative Health Research, 20, 987-998.

OPJORDSMOEN, S. \& FOSSÅ, S. D. 1994. Quality of life in patients treated for penile cancer. A follow-up study. British Journal of Urology, 74, 652-657. 
PIZZOCARO, G., ALGABA, F., HORENBLAS, S., SOLSONA, E., TANA, S., VAN DER POEL, H. \& WATKIN, N. A. 2010. EAU Penile Cancer Guidelines 2009. European Urology, 57, 1002-1012.

ROMERO, F. R., RICHTER PEREIRA DOS SANTOS ROMERO, K., DE MATTOS, M. A. E., CAMARGO GARCIA, C. R., DE CARVALHO FERNANDES, R. \& CARDENUTO PEREZ, M. D. 2005. Sexual function after partial penectomy for penile cancer. Urology, 66, 12921295.

SAMPSON, H., BLOOR, M. \& FINCHAM, B. 2008. A Price Worth Paying? Considering the 'Cost' of Reflexive Research Methods and the Influence of Feminist Ways of 'Doing'. Sociology, 42, 919-933.

SCHWALBE, M. \& WOLKOMIR, M. 2001. The masculine self as problem and resource in interview studies of men. Men and Masculinities, 4, 90 - 103.

WALLS, P., PARAHOO, K., FLEMING, P. \& MCCAUGHAN, E. 2010. Issues and considerations when researching sensitive issues with men: examples from a study of men and sexual health. Nurse Researcher, 18, 26-34.

WHITE, A. \& JOHNSON, M. 1998. The complexities of nursing research with men. International Journal of Nursing Studies, 35, 41-48.

WHITE, A. D. S., B. DE VISSER, R. HOGSTON, R. AAGE MADSEN, S. MAKARA, P. RICHARDSON, N. ZATONSKI, W. 2011. The State of Men's Health in Europe. 